\title{
ALFABETIZAÇÃO E LETRAMENTO NAS ÁGUAS DO SÃO FRANCISCO
}

\author{
Rossana Regina Guimarães Ramos HENZ \\ (Universidade Federal de Pernambuco) \\ rossanaramos@cortezeditora.com.br
}

\begin{abstract}
Resumo: $O$ presente artigo discute as relações entre as cartilhas de alfabetização (livros didáticos) atualmente utilizadas e as concepções contemporâneas de Leitura e Letramento. $O$ estudo realizou-se especificamente em uma escola municipal de Petrolina - PE, localizada em uma ilha do Rio São Francisco - llha do Massangano em que a cartilha Alfa e Beto de João Batista de Oliveira é utilizada como suporte de leitura para alfabetização dos alunos do $1^{\circ}$ ano do Ensino Fundamental. Uma caracterização do espaço geográfico e social evidencia essa ilha como uma pequena comunidade de pescadores e agricultores que sobrevivem dessas atividades ou de pequenos serviços na cidade. Metodologicamente, a pesquisa realizou-se por meio da observação do trabalho pedagógico realizado pela professora e pelas interações dos alunos com o livro. Foram utilizados os recursos da pesquisa qualitativa no sentido de que os dados colhidos fossem analisados e comparados nas perspectivas linguística e social, no que se refere às concepções de leitura e letramento. Os resultados apontaram para uma divergência notória entre as propostas de atividades - temas e subtemas - da cartilha e os interesses sociais dos alunos. Como praticamente o único suporte de leitura escolar utilizado na escola, a cartilha tem preponderância no trabalho pedagógico, ou seja, as leituras e escritas dos estudantes praticamente se resumem a esse gênero escolar. Os resultados da pesquisa tornaram evidente um afastamento entre "o que lê e o que se vive" nesta ilha, provocando lacunas não somente no processo de alfabetização, mas também na proposta escolar de se formar leitores.
\end{abstract}

Palavras-chave: Leitura. Escrita. Letramento. Cartilhas

\section{INITIAL READING INSTRUCTION AND LITERACY ON SÃO FRANCISO RIVER WATERS}

Abstract: This article discusses the relationship between one literacy primer (textbook) currently used and contemporary conceptions of reading and literacy. The study was conducted specifically in a municipal school, located on Massangano island in the São Francisco River - Petrolina, Pernambuco, Brazil. In this context the elementary school primer Alfa and Beto by João Batista de Oliveira is used as a reading support for students of the 1st grade of elementary school. A characterization of the geographical and social space shows this island as a small community of fishermen and planters who make a living either from these activities or from services done to residents in town. Regarding 
methodological design, the research was carried out by observing the pedagogical work developed by the teacher and the students' interactions with data can be analyzed not only under a linguistic but also under a social perspective in relation to reading conceptions and literacy. The results indicate a marked divergence between the proposed activities - topics and subtopics in the literacy primer used in the learning context and the students' social interests. It can be said that the literacy primer is the sole reading material available; therefore, it predominates over the pedagogical work. In other words, this teaching material makes the students have little or no access to different genres. The research results indicate the existence of a clear distance between "what the students read and what they live" on this island. Consequently, this distancing creates some gaps not only in the literacy process but also in development of the students' reading skills.

Keywords: Reading. Writing. Literacy. Literacy primer.

\section{Introdução}

Os estudos de alfabetização do ponto de vista histórico evidenciam relações para a problemática do desenvolvimento social, avanço econômico, religião, escolarização etc., bem como a interação entre o oral e escrito e as relações entre alfabetização e analfabetismo. Valem-se também os estudiosos dessa área, como é o caso de FRAGO (1993), da análise das instâncias ou agentes, evolução e difusão, meios e procedimentos, objetivos e consequências, práticas e usos, como também o debate em torno de problemas de quantificação.

A iniciativa de realizar a presente pesquisa se justifica, a priori, por uma realidade social que diz respeito ao processo de alfabetização no Brasil que ainda se constitui nos dias de hoje como uma tarefa complexa, tendo em vista o número ainda elevado de pessoas analfabetas no país. De acordo com a mais recente Pesquisa Nacional por Amostra de Domicílios (Pnad), feita pelo Instituto Brasileiro de Geografia e Estatística (IBGE) em 2012 e divulgada em setembro de 2013, a taxa de analfabetismo de pessoas de 15 anos ou mais foi estimada em 8,7\%, o que corresponde a 13,2 milhões de analfabetos no país. Este número se agrava quando se analisa particularmente algumas localidades (Estados e Municípios) das regiões norte de nordeste em que o índice de analfabetos adultos varia entre $40 \%$ e $50 \%$. Assim sendo, discutir a alfabetização e seus processos 
didáticos, ainda é relevante, não só do ponto de vista político-social, mas, sobretudo da perspectiva pedagógica que implica estudos sobre teorias, métodos e técnicas utilizadas em programas e planos didáticos os mais variados ao longo do país.

A questão é complexa e de natureza vária. O que se observa de um modo geral, é um distanciamento entre as novas perspectivas teóricas na área de alfabetização e as práticas utilizadas. Seguimos ao longo do tempo vislumbrando um panorama educacional que evidencia o desenvolvimento de propostas de alfabetização com base na teoria da Psicogênese da Escrita (FERREIRO \& TEBEROSKY, 1986) e das propostas de letramento, mas ainda é vasta a aplicação de modelos alicerçados pelos métodos tradicionais sintéticos e analíticos, sobretudo o fônico que prioriza a relação fonema/grafema. Assim sendo, convivem atualmente pelo menos duas abordagens: uma como base nos métodos, que priorizam os aspectos mecânicos da língua, e as concepções de Letramento que implicam novos olhares sobre a alfabetização (aquisição do código escrito), discutindo o papel e os efeitos da escrita em uma sociedade grafocêntrica. (SOARES, 2006).

Desse modo, nosso objetivo, com a presente pesquisa, é observar e discutir os efeitos da aplicação do método fônico apresentado por um determinado material - a cartilha Alfa e Beto - para um grupo de alunos de uma região específica - uma ilha do Rio São Francisco - no que se refere às questões de letramento, na perspectiva das relações socioculturais existentes nessa localidade e o texto da cartilha.

\section{1 - Processos teóricos e metodológicos}

A aquisição da escrita e da leitura (alfabetização) vem sendo discutida na última década com vistas para o Letramento, campo de estudo que consiste na observação dos saberes, nas fontes de conhecimento humano que são várias e advindas das mudanças que se operam interna e externamente na sociedade. Esse quadro social revela a herança cultural que, segundo Goody \& Watt (2006), é transmitida por meio de três itens distintos. Um primeiro que evidencia uma planta material, ou seja, que inclui as fontes naturais disponíveis, como espaços e tempos delimitados por uma comunidade. Um 
segundo que reflete as práticas sociais que se repetem em determinadas culturas como a culinária, a agricultura, a educação das crianças etc. O terceiro item, segundo os autores, é indubitavelmente canalizado por meio de palavras, ou seja, pelo conjunto verbal (a língua) de uma comunidade.

Com vistas para um estudo que tem como base as concepções de Letramento, é que buscamos na relação língua/sociedade as devidas fontes de conhecimento geral e específico sobre a relação língua/sociedade/conhecimento. A concepção de Letramento é recente e envolve diversos aspectos. O que pudemos verificar em pesquisas é que o letramento está além da alfabetização. Trata-se de um processo abrangente que diferencia o decodificador do leitor. A ideia começa a ser discutida na França, em 1976, por Foucambert que iniciou um movimento teórico e prático, cujo objetivo estava na substituição de uma Pedagogia da Alfabetização - a querela dos métodos voltada para a formação do decifrador - para uma Pedagogia da Leiturização, esta, sim, segundo o autor, comprometida com a formação do leitor.

A concepção de Foucambert chega ao Brasil quase duas décadas depois por meio da publicação de sua obra $A$ Leitura em Questão, uma coletânea de textos polêmicos produzidos ao longo de vários anos. O alvo principal de sua tese está centrado em um programa desafiador que propõe a desescolarização da leitura. Desescolarizar a leitura significa que, tanto em relação às crianças quanto aos adultos, todas as instâncias educativas devem cuidar de formar 0 leitor, ou seja, a tarefa de formar leitores é um assunto comunitário que implica uma ação conjunta da sociedade. Implica também esse conceito de desescolarização a desvinculação da leitura dos textos de livros didáticos para a adoção de uma leitura do texto funcional, ou seja, da inserção de novas fontes escritas em que se incluem jornais, revistas, letreiros, textos instrucionais (receitas, manuais, bulas etc.), cartas, documentos, romances, entre outros.

A proposta de Foucambert (1994) passou a ser estudada e desenvolvida em várias áreas de estudo, sobretudo na Educação e nas Ciências Linguísticas. No Brasil, da ideia de formar leitores surge a constatação de especialistas de que à medida que o problema do analfabetismo vai sendo superado, evidencia-se um novo fenômeno: o do analfabeto funcional, ou seja, 
do indivíduo que é capaz de decifrar o texto escrito, mas que não adquire competência para usar a leitura e a escrita em sua prática social.

Com a denominação de letramento, a concepção que analisa a relação decifrador/leitor passa a ser discutida na Sociolinguística e na Psicolinguística, cujo enfoque está na prática social da escrita. Letramento ganhou estatuto de termo técnico e passou a ser usado frequentemente pelos especialistas que tratam da questão da formação do leitor.

Denota-se a diferença entre saber ler e escrever, ou seja, ser alfabetizada, e aquele que participa ativamente das ações permeadas pela leitura e pela escrita nas relações sociais em que se envolve, ou seja, ser letrado. Alfabetizado é aquele que aprendeu a ler e escrever, ou seja, que adquiriu uma tecnologia, já o letrado apropria-se da leitura e da escrita, utilizando-as de forma própria, autoral, que responde competentemente às exigências de uma sociedade grafocêntrica, como enfatiza Soares (2006). A palavra Letramento surge então da necessidade de se ter uma expressão que dê nome a esse fenômeno muito mais abrangente do que o termo alfabetização pode alcançar, porque envolve práticas e eventos que estão além do conhecimento escolarizado, mas que abrange todas as ações vivenciadas pelo aluno na totalidade da sua vida.

Aos poucos, os estudos foram se alargando para descrever as condições de uso da escrita, a fim de determinar como eram e quais efeitos das práticas de letramento em grupos não minoritários, ou em sociedades não industrializadas que começavam a usar a escrita com uma "tecnologia" de comunicação dos grupos que sustentavam o poder. Isto é, os estudos já não mais pressupunham efeitos universais do letramento, mas pressupunham que os efeitos estariam correlacionados às práticas culturais e sociais dos diversos grupos que usavam a escrita (KLEIMAN,1995).

O que podemos inferir do processo de letramento é que a prática social da escrita e da leitura deve ser aplicada com o objetivo de formação de leitores e escribas capazes de transformar a realidade social por meio dos textos que leem e escrevem. Desse modo, o que viabiliza a prática do letramento é o conhecimento do contexto social, de preferência, sob um olhar atento das diversas formas em que se apresenta. 
Nesse sentido, entendemos, por exemplo, que a criança desde o início de sua escolarização deve entrar em contato diretamente com o texto, sobretudo aquele que faça algum sentido para ela. Apresentar sílabas e letras como preconizam os métodos tradicionais (sintético e analítico), a priori, não estabelece os vínculos necessários ao letramento, melhor dizendo, à formação do leitor. Não que pessoas alfabetizadas por esses métodos não venham a se tornar leitores mais tarde, mas, certamente, descobrir na mais tenra idade a função social da leitura é um incentivo ao entendimento do ato de ler como uma forma de prazer, informação dentre outros benefícios em uma sociedade grafocêntrica.

Em Hamilton (2002), encontramos a ideia de múltiplos letramentos, ou seja, Letramentos, destacando os conceitos de letramentos dominantes institucionalizados - e letramentos locais - vernaculares ou autogerados. Todavia, a autora não os vê separadamente, mas sim, interligados por uma relação que se estabelece socialmente. Os letramentos dominantes estão associados a organizações formais tais como a escola, as igrejas, o local de trabalho, o sistema legal, o comércio, as burocracias. Estão sob o controle de agentes, quais sejam: professores, autores de livros didáticos, especialistas, pesquisadores, burocratas, padres e pastores, advogados e juízes.

Já os letramentos vernaculares têm origem no cotidiano, no processo assistemático da vida social, nos acontecimentos, na cultura, nos hábitos corriqueiros e, por isso, não têm valor e são desprezados pela cultura social e seus agentes. Street $(2014$, p.130) menciona a questão do letramento escolar em comparação ao letramento social, denominado por ele como ideológico, da seguinte forma:

A institucionalização de um modelo particular de letramento opera não só por meio de formas particulares de fala e de textos, mas no espaço físico e institucional, que é separado do espaço "cotidiano" para fins de ensino e aprendizagem e que deriva de construções sociais e ideológicas mais amplas do mundo social e construído.

Do ponto de vista pedagógico, devemos nos debruçar sobre os campos do conhecimento que ampliam e especificam o objeto a ser estudado. Tomamos como exemplo o campo da História que traz para a sala de aula as diversas produções humanas em seu espaço/tempo, desde imagens 
particulares - fotografias, cartas, convites, diários etc. - até as imagens públicas dos livros e jornais em circulação como fonte de informação e construção dos textos que devem refletir a prática social. Nesse sentido, também se estabelece a pesquisa em Geografia, cujo olhar debruça-se sobre a paisagem, não somente do entorno, mas, por meio dos registros de imagem, de outros lugares distantes da visão in loco. De posse das ferramentas sociais, ou seja, do conhecimento da realidade, o indivíduo utiliza a tecnologia da escrita para reconstruir os fatos e, desse modo, analisá-los em uma perspectiva mais próxima de seu próprio entendimento.

Com relação aos aspectos metodológicos, a presente pesquisa, de natureza qualitativa, realizou-se na Escola Santo Antônio localizada em uma ilha no Rio São Francisco, denominada Ilha do Massangano, Petrolina - PE, na região do semiárido. Nosso contato inicial com a comunidade deu-se a partir de uma solicitação da direção da escola à universidade (UPE - campus Petrolina) no sentido de auxiliar na "recuperação" de alunos do $3^{\circ}$ e $4^{\circ}$ ano do Ensino fundamental, considerados como tendo "dificuldades" de leitura e escrita e, portanto, em defasagem no processo de alfabetização. Por meio de um projeto de extensão realizado por esta pesquisadora e duas alunas de mestrado (UNICAP e PROFLETRAS), a solicitação foi atendida, ocasião em que pudemos desenvolver práticas pedagógicas e de pesquisa que resultaram no presente artigo.

Para o processo de pesquisa, determinamos como ponto de partida uma entrevista com professores a respeito do método e das questões que ali se apresentam com relação ao processo de alfabetização. O passo seguinte foi o contato com as crianças cuja faixa etária está entre 8 e 11 anos. Em conversa informal com o grupo, verificamos que a maioria trabalha na "roça" ou em serviço doméstico no contra turno da escola. Antes de iniciarmos o trabalho pedagógico propriamente dito, fizemos um reconhecimento do espaço físico e social da região. Durante caminhadas pelos $4.000 \mathrm{~m} 2$ da ilha, tomamos conhecimento de que vivem ali por volta de 600 habitantes. Os moradores sobrevivem principalmente da agricultura e da pesca, mas muitos saem para trabalhar nas cidades de Petrolina e Juazeiro - BA. Na escola com 150 alunos, funcionam a Educação Infantil e o Ensino Fundamental. 
No terceiro momento, propusemos às crianças uma oficina de marionetes para montagem de uma peça teatral. Os doze alunos envolvidos na tarefa, mostraram-se entusiasmados com a ideia de produzir os personagens e em seguida o texto oral para apresentação. No encontro seguinte, solicitamos que escrevessem sobre a experiência vivenciada na oficina. Nesta etapa, foi possível observar em que níveis de escrita e leitura encontravam-se as crianças, a fim de que pudéssemos iniciar o trabalho pedagógico. Em encontros frequentes, durante um ano, conversamos longamente com os professores sobre as questões inquietantes no processo de alfabetização dos alunos. Realizamos também diversas atividades como caminhadas pela ilha, momento em que observávamos e descrevíamos a paisagem, coletávamos histórias (lendas) sobre o local. Durante este período assistimos a apresentações do Samba de Veios, ritmo musical característico dos moradores da ilha.

\section{2 - Sobre o método e o material didático}

Generalizadamente chamado de cartilhas, o material didático da alfabetização constitui um gênero amplamente divulgado ao longo do tempo como base no processo inicial da aquisição da leitura e da escrita. Conforme Barbosa (1994, p. 54), a escola "Utiliza como recurso de base um suporte material impresso, que tem sua origem ligada aos silabários do século XIX: a cartilha". Embora, mantendo o mesmo propósito, o de alfabetizar, as cartilhas sofreram mudanças ao longo do tempo. Tanto na aparência como nas formas de apresentação de seus conteúdos, as cartilhas foram influenciadas por teorias advindas de determinadas áreas como da Psicologia e da Linguística. Produzir um estudo desse gênero significa, portanto, analisar aspectos internos e externos que devem buscar em outras ciências a sua própria constituição.

Como em todo município de Petrolina, na escola da ilha, também utiliza como material para a alfabetização a cartilha (programa) Alfa e Beto que é um pacote educacional que contém livros de alfabetização, Ciências e Matemática. Com base fonética, o material prioriza as relações entre fonemas e grafemas, ou seja, o processo de alfabetização é sistematizado das partes para o todo. 
Seu caráter comercial é evidente em sua apresentação no site ${ }^{1}$. Sem qualquer parâmetro científico, o material é apresentado da seguinte forma:

O Programa Alfa e Beto de Alfabetização foi desenvolvido para alunos do $1^{\circ}$ ano do Ensino Fundamental, série em que a alfabetização deve acontecer. $O$ objetivo é assegurar que todos os estudantes dominem o nível básico de fluência em leitura e escrita, o que aumenta as chances de avançarem com sucesso na vida escolar e concluírem seus estudos no tempo adequado. Para isso, o IAB utiliza o método fônico, comprovadamente o mais eficaz para promover a alfabetização de crianças e adultos.

Em entrevista com os professores, tomamos conhecimento de que o material é o único recurso didático utilizado, estando vetada pela coordenação pedagógica a utilização de qualquer proposta alternativa. Isto é, não é dado ao professor o direito de recusar-se a aplicar esse material.

\section{3 - Análise}

A primeira etapa da pesquisa realizou-se por meio de entrevistas com professores do pré II e do $1^{\circ}$ ano do Ensino Fundamental, tendo em vista nosso interesse em coletar dados sobre as relações entre o material didático e a proposta de alfabetização e letramento.

Inicialmente, perguntamos quais eram suas impressões sobre o material didático em questão. Em resposta, os professores alegaram que o maior problema do material está na descontextualização, ou seja, na distância entre o que é lido do é vivido pelos alunos, o que, segundo os professores, é a causa principal do desinteresse das crianças pela leitura e escrita. Dizem eles: "o livro não tem nada a ver com a realidade das crianças".

A pergunta seguinte se constituiu em saber em que medida ocorre esse desinteresse. Os dois professores entrevistados responderam que as atividades de modo geral são repetitivas (cansativas) e não chamam atenção dos alunos, a exemplo da que apresentaremos a seguir ${ }^{2}$.

\footnotetext{
${ }_{1}^{1}$ http://www.alfaebeto.org.br/produtopagina

${ }^{2}$ As imagens a seguir foram retiradas do Livro 2 - Programa Alfa e Beto de Alfabetização Letras e Sons.
} 


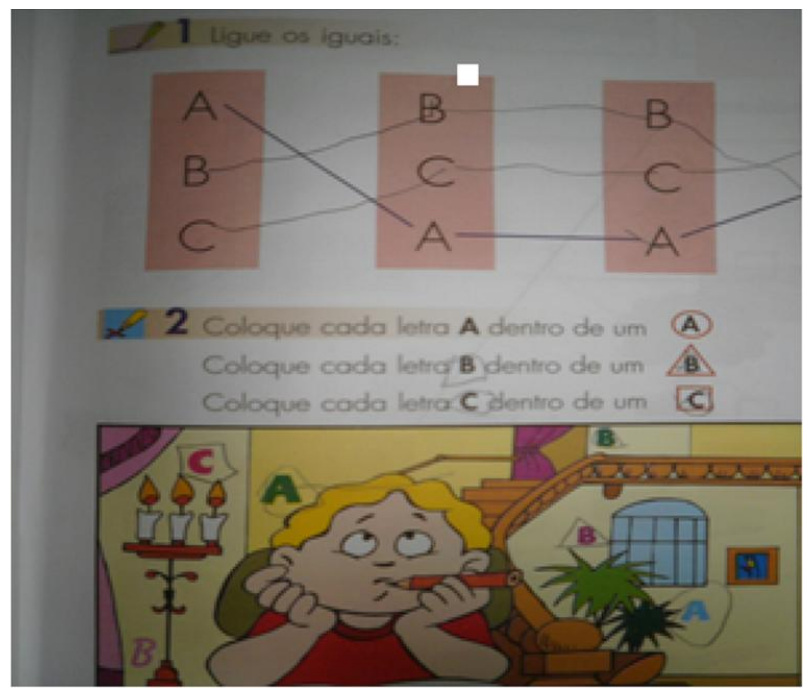

Figura 1 (p. 5)

Sobre a imagem, os professores relataram que os alunos perguntam: "Isso é uma história? O que tem que fazer aqui?" O exercício que se repete até o final da cartilha, variando apenas as letras que vão até o $Z$, não produz qualquer sentido. A atividade apresenta letras soltas sem qualquer relação contextuais: é apenas um exercício de reconhecimento dos grafemas.

Sobre isso, Cagliari (2004, p.200) comenta:

O mundo da linguagem é o mundo dos textos. Por essa razão, o professor deve tentar, sobretudo no início, criar situações em sala de aula em que predominem o texto. Por outro lado, o professor deve tomar cuidado quando exemplifica com pedaços de fala.

Outra questão que aqui evidenciamos ainda sobre a falta de interesse dos estudantes, de modo geral, pela produção textual, se localiza no tipo de proposta metodológica em que alunos devem escrever palavras soltas ou sílabas ou letras, sem qualquer tipo de contextualização, apenas como exercício mecânico de escrita. Sobre isso, Passarelli (2004) informa que tal resistência se dá em função da distância entre os temas propostos para as redações escolares e a realidade social em que vivem esses estudantes, conforme vemos na imagem seguinte: 


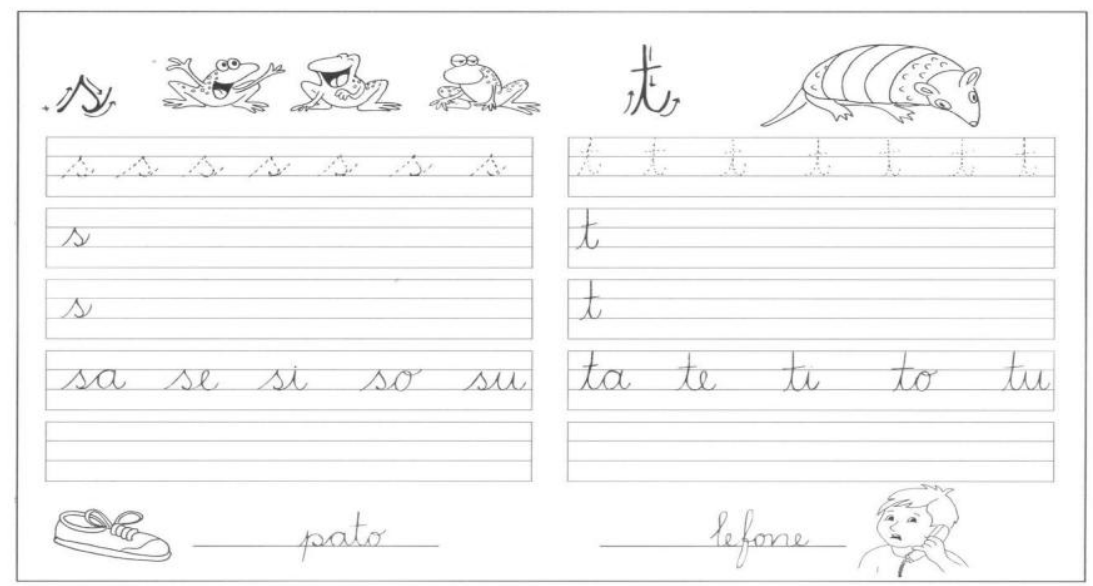

Figura 2 (p. 69)

As análises realizadas no processo de pesquisa apontaram, sobretudo, para questões que envolvem as relações entre o letramento local - autogerado - e as leituras operadas pelos alunos. Na primeira figura, observamos imagens que devem ser observadas para que sejam marcadas as que não pertencem à história.

\section{Marque com um $\mathbf{X}$ os quadros que não pertencem a esta história:}
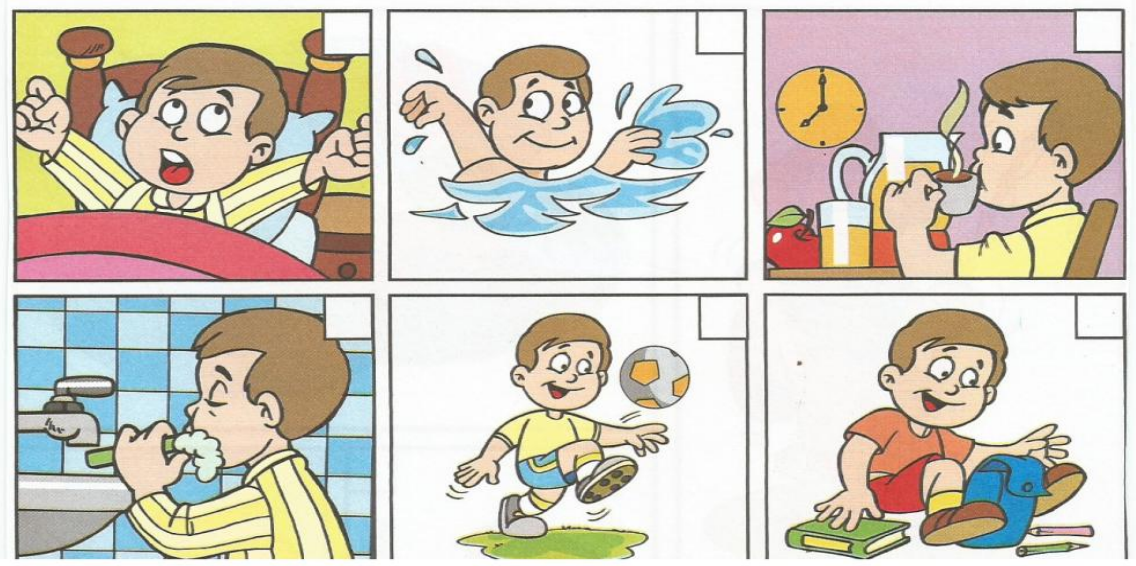

Figura 3 (p. 11)

Ao observar a figura, três alunos disseram que a figura que não pertencia à história era a em que o menino se espreguiça na cama. Ao perguntarmos por que, responderam que crianças dormem em rede, a maioria não tem cama. Questionamos a imagem do menino nadando, se de fato estava no contexto da 
história. Todos responderam que sim, pois antes de ir para a escola, tomam banho de rio (Rio São Francisco). Um aluno considerou que a história estava toda incorreta porque pela manhã as crianças pequenas trabalham na roça e somente depois do almoço vão à escola. Questionamos o fato de que aqueles podiam ser crianças de outro lugar, por exemplo, "da rua"3. Os alunos responderam que não sabem como é a vida das crianças que não vivem na ilha.

$\mathrm{Na}$ perspectiva do letramento, podemos analisar a questão conforme o que apresenta Street (2014, p.137-138):

Uma pergunta-chave para a pesquisa futura é como a afirmação de autoridade e a alocação dos participantes em papeis e relacionamentos específicos se inscrevem em eventos e práticas de letramento particulares. A princípio, isso pode nos levar a concluir que a concepção de letramento associada à escolarização e à pedagogia, em particular à ênfase no Ensino-Aprendizagem, está transformando a rica variedade de práticas letradas evidentes nos letramentos comunitários em uma prática única, homogeneizada.

O texto (as Imagens), de antemão, propõem, segundo uma leitura localizada em um determinado segmento social e geográfico, que as crianças durmam em camas e não nadem antes de ir para a escola. Todavia, para esse grupo de alunos, em face de sua planta material (Hamilton, 2002), a leitura se faz por meio de uma aproximação entre as práticas sociais e o letramento escolar que, na maioria das vezes, despreza os contextos e as práticas sociais dos indivíduos. A questão, conforme assevera Street (2014), é saber em que medida os professores - muitos não sendo moradores da ilha - estão preparados para colocar em prática as teorias que preconizam a diversidade cultural das localidades como importante ponto de partida para a ampliação do letramento.

A figura 2 propõe que os alunos marquem com $D$ a figura que não começa com a letra D.

\footnotetext{
${ }^{3}$ Termo utilizado para os locais fora da ilha, às margens do rio.
} 


\section{* 4 Marque com um $\mathbf{D}$ a figura que não começa com a letra $\mathbf{D}$ :}

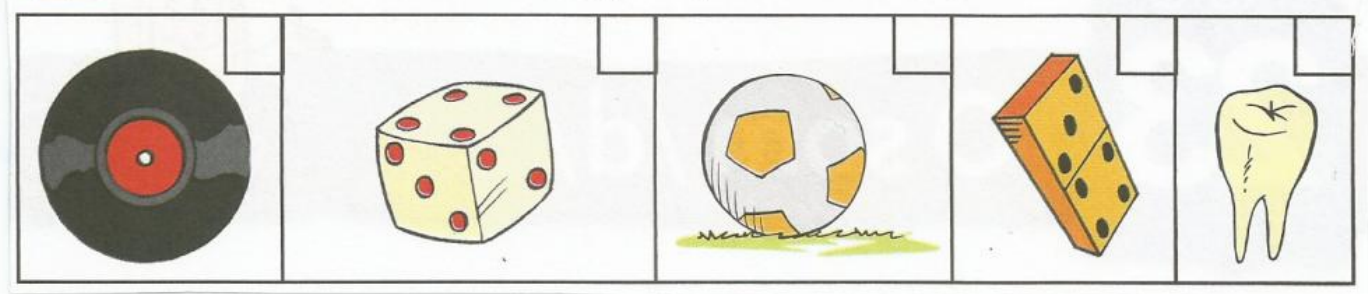

Figura 4 (p. 109)

Em relação a esta atividade, ao serem informados de como deveriam realizá-la, os alunos excluíram o disco, a bola e o dente. Questionamos a figura do disco perguntando-Ihes o que viam ali. Todos responderam que era um pneu. Quanto ao dente, disseram que parecia um tamborete (um banco), mas que estava estranho porque só tinha duas pernas.

Nesse caso, a questão se torna ainda mais complexa, já que a relação imagem-objeto é cenário para o processo de alfabetização. Tendo em vista que devemos levar em conta nas práticas pedagógicas os aspectos culturais e transculturais que auxiliem os alunos a situarem-se em suas práticas de letramento linguístico, situações como esta vão de encontro, por exemplo, a uma abordagem da Consciência Crítica de Fairclough (1992, p. 22), que nos indica que "qualquer evento discursivo (isto é, qualquer exemplo de discurso) é considerado simultaneamente um texto, um exemplo de prática discursiva e um exemplo de prática social". Nesta teoria, o discurso é entendido como constituinte do social, como um modo de ação, pois é uma das maneiras pelas quais as pessoas podem agir sobre o mundo e sobre os outros, mas é também visto como uma forma de representação, pois nele valores e identidades são representados de forma particular. Os discursos são concebidos como não apenas reproduzindo entidades e relações sociais, mas também como as construindo de diversas maneiras, cada uma das quais posicionando os sujeitos sociais também de diferentes maneiras.

\section{Considerações finais}


Com base na pesquisa, compreendemos que nesta situação específica local e grupo social - as relações entre a cartilha e o processo de alfabetização e letramento produzem efeitos negativos, considerando que além de priorizar a escrita mecânica - letras, sílabas e palavras soltas - o programa Alfa e Beto, por ser um material produzido em série para todo o país, não atende às necessidades de contextualização local. Práticas sociais, cultura e variações linguísticas locais não fazem parte do texto cartilhado em questão.

Para os professores da escola, a descontextualização, ou seja, a distância entre o que é lido e o que é vivido pelos alunos é a causa principal do desinteresse das crianças pela leitura e escrita. Nesse sentido, Cagliari (2004, p. 209) assevera que:

Se o professor alfabetizador deve trabalhar, sempre que possível com textos, os alunos também devem estar sempre envolvidos com a problemática da linguagem, analisando-a dentro de um contexto real de uso, ou dentro da própria linguagem, como é o caso das relações entre letras e sons.

Com isso, é possível fazer uma crítica à aplicação de propostas pedagógicas, ainda amplamente utilizadas, que consideram a escrita e a leitura como algo mecânico, voltado para a decodificação ou que, do ponto de vista ideológico, estão repletos de concepções distantes do contexto dos grupos sociais.

Ainda que parciais, nossas conclusões sobre a pesquisa apontam para a possibilidade de uma reflexão mais profunda sobre as discussões que envolvem as noções de letramento em contextos de ensino que relacionam leitura, escrita e práticas sociais. Nessa perspectiva teórica, é possível que se abram novas práticas escolares que atendam a um conhecimento premente dos novos "textos" vinculados às funções sociais da escrita e aos saberes próprios, autogerados por crianças e adultos de localidades específicas.

\section{Referências bibliográficas}

ALFA e BETO. Disponível em: http://www.alfaebeto.org.br/produtopagina/?slug =descricao-15\&slug_pai=programa-alfa-e-beto-de-alfabetizacao-2

BARBOSA, José Juvêncio. Alfabetização e leitura. São Paulo: Cortez, 1994. 
CAGLIARI, Luiz Carlos. Alfabetizando sem o bá-bé-bi-bó-bu. São Paulo: Scipioni,2004.

FAIRCLOUGH, Norman. Critical discourse analysis and the marketization of public discourse: the universities. Discourse \& Society, Vol. 4 (2), 1992. FERREIRO, Emília \& TEBEROSKY, Ana. Psicogênese da língua escrita. Porto Alegre: Artes Médicas, 1986.

FOUCAMBERT, Jean. A leitura em questão. Porto Alegre: Artes Médicas, 1994.

FRAGO, Antônio Viñao. Alfabetização na sociedade e na história: vozes, palavras e textos. Porto Alegre: Artes Médicas, 1993.

GOODY, Jack e WATT, lan. As consequências do letramento. São Paulo: Paulistana, 2006

HAMILTON, M. Sustainable literacies and the ecology of lifelong learning. In: HARRISON, R. R. F.; HANSON, A.; CLARKE, J. (Org.). Supporting lifelong learning: perspectives on learning. London: Routledge/Open University Press, 2002.

IBGE. Disponível em: http://www.ibge.gov.br/home/estatistica/populacao/censo 2010/indicadores_sociais_municipais/tabelas_pdf/tab28.pdf

KLEIMAN, A. B. (org.). (1995). Os significados do letramento: uma nova perspectiva sobre a prática social da escrita. Campinas: SP, Mercado das Letras.

PASSARELLI, Lilian Ghiuro. Ensinando a escrita: o processual e o lúdico. São Paulo: Cortez, 2004.

SOARES, Magda. Letramento: Um tema em três Gêneros. Belo Horizonte: Autêntica. 2006.

STREET, Brian. Letramentos sociais: abordagens críticas do letramento no desenvolvimento, na etnografia e na educação. São Paulo: Parábola, 2014. 
Artigo recebido em: 20 de julho de 2015

Artigo aprovado em: 20 de setembro 2015

Sobre a autora:

Rossana Regina Guimarães Ramos Henz possui doutorado (2005) e mestrado (2011) em Língua Portuguesa pela Pontifícia Universidade Católica de São Paulo (2005) e graduação em Licenciatura em Letras - Faculdades de Educação Ciências e Letras Notre Dame (1986) e graduação em Pedagogia om Habilitação em Administração Escolar (1996) pela Faculdade de Educação Antônio Augusto Reis Neve. Atualmente é professora adjunta do curso de Letras e do Programa de Pós-Graduação (Mestrado Profissional) e do PROFLETRAS - nos campi de Garanhuns e Mata Norte. 